The Social Sciences 14 (11): 361-369, 2019

ISSN: $1818-5800$

(C) Medwell Journals, 2019

\title{
Polar Thinking among University Students
}

\author{
Madyan Noori Talag and Asseel Lateef Ketab \\ Ministry of Higher Education and Scientific Research, \\ Department of Educational and Psychological Sciences, \\ Faculty of Education for Humanities, Babylon University, Hillah, Iraq
}

\begin{abstract}
The current research aims to identify: Polar thinking among university students. The statistical significance of Polar thinking among university students according to the variables of gender (male and female) b specialization (human sciences). In order to achieve the goals of the research, the researchers adopted the Polar thinking standard and applied it to the students of the universities of the middle euphrates after extracting the psychometric properties.
\end{abstract}

Key words: Polar, statistical, research, proposals, sciences, variables

\section{INTRODUCTION}

Problem research: Recent research has tended to study some important psychological characteristics that have a direct impact on changing human life. Thinking is one of the most studied topics in the fields of psychology, especially, cognitive psychology. All philosophical, intellectual and educational schools have been used to help the individual to become more capable of confronting difficulties, challenges and problems encountered in all areas of social, economic, educational and moral life.

And that what we are witnessing today in our era of thinking is the need to experiment with new and atypical methods in solving problems, especially, we live in a time of speed, technology and modern means with the many difficulties, challenges and problems that think is the tool of reason in the face of the information revolution facing society today because it represents a strong scientific base to keep up with the rapid changes that have taken place in all aspects of life. To make this a strong base capable of meeting challenges and difficulties, it must be properly developed.

Beck (1990, 1993, 2000) suggests that automatic ideas lead to cognitive distortion which is a consequence of it. Examples of personalization are personal ideas which are triggered by special stimuli that lead to emotional responses, i.e., interpretation of events from the individual's point of view, Polar thinking or polarized thinking which is located on one of the opposite sides, either white or black, since, the individual does not give himself a large space to decide whether it is successful or a skillful or wonderful failure. Beck also believes that psychological disorders result from the inconsistency between the internal cognitive system of the individual and Muth the external ways in which that individual is exposed and analyzed by the internal cognitive system that distinguishes him. Since, the disruption of reality on the part of the individual in the event of disturbances leads to a certain degree of disorder of thinking which creates automatic or automatic ideas seem acceptable from the point of view of the individual and then be reasonable or acceptable to him. He interprets all events as applicable to him and is therefore, centered on himself which is known as personal representation and is characterized by radical thinking which is known as polarized or polarized thinking (Muhammad, 2000).

The importance of research: Many studies and researchers have confirmed that some individuals who are subjected to psychological trauma may become mentally rigid and then look at things in an extreme negative way. Either a black look or a white look and they do not tend to mediate thinking which means that they have a Polar mindset. Educated and educated can overcome the economic, political and social problems and the nature of education in the university institutions and what the university student exercises of scientific, social and cultural activity may make him inclined to the middle of thinking and so, may not have a

olar mind, although, sold which confirmed that middleschool students suffer from polarized thinking, so, it was necessary to conduct a pilot program to reduce polarized thinking.

Where individuals who are thinking extremist either white or black is a person who can not tolerate ambiguity and rejects the risk in everything he tends to deal with the constants and is characterized by its response to

Corresponding Author: Madyan Noori Talag, Ministry of Higher Education and Scientific Research,

Department of Educational and Psychological Sciences, Faculty of Education for Humanities,

Babylon University, Hillah, Iraq 
extremism their positions with others with or against and is seen as dialectical areas as white or black only (Zawawi, 2011).

Where individuals are rigid fanatics who are closed with the ideas they believe and are characterized by arrogance, impulsiveness and marginalization in their decision and their lives where the person believes one idea and one opinion.

The researchers focus on psychological therapy and behavior modification, since, 1965 on intensive studies and experiments to examine the effects of the individual's erroneous beliefs about himself and others. This research suggests that there is strong evidence that behind every emotional act of anger, aggression, withdrawal, the impulse, the building and the pattern of perceptions and beliefs adopted by the individual about life and its problems and emotional behavior changes according to these perceptions (Ibrahim, 1990, 1993, 2000).

Rushman points out that radicalism or extreme thinking is characterized by an extreme response, either accepting or rejecting absolute acceptance, regardless of the content and reasonableness of evil. Their behavior is resistant to proof presented to them and refuses to listen to others or to discuss the other party and neglect people who do not agree with him in the opinion is to close the discussions that contradict his ideas and does not like change in the patterns of behavior and does not like change even at the family level and the world around him (Azirjawi, 2007).

The concept of Polar thinking is linked to the cognitive schema (negative), although, it has been derived largely from the information processing (Cognitive Cognitive Enformation) which emphasized the role of wrong and fixed schemes or structures of information structures in the process of organizing ideas, emotions and perceptions and that Polar thinking produces causes and symptoms related to the negative effects of emotions such as depression and anxiety (Beck, 1991, 2000, 1995).

Where the person knows himself and others and attitudes and the world according to extreme categories extremist and tends this type of thinking to be absolute and Amal a little hope for example, a mother who sees herself very bad not frustrating of her little child and see other mothers have patience for their children, so, see other mothers general is better than this type of thinking is completely unrealistic either white or black (Mostafa, 2008).

The negative thoughts and perceptions of the individual about himself and other individuals in the society in which he lives and his vision of the weaknesses and unpleasant incidents and defects and errors and not to look at the near future except dark corners and pessimistic make him suffering from mental disorders and in light of the treatment in this theory is to remove these perceptions are negative and extreme ideas (Stoudmire, 1998).
Polar thinking may dominate the thinking of some individuals, so, it is difficult for them to analyze knowledge and it seems that the perspective based on the scheme of self applies to Polar thinking in the sense that the characteristic characteristic of this thinking is not only the weakness or inability of the individual to deal functionally with the environment because this thinking is characterized by hardness and closure also and that Polar thinking examines the information in a biased and unusual and expels any information he sees inconsistent with their ideas or not consistent with what is in his thinking and does not fit with the people who oppose his ideas and pick any idea, no matter what simple the idea lasted to be supportive. Because in his information scheme to compose the whole of his cognitive perspective and deal with others (Fiske and Taylor, 1991).

Frankel Brunswick states that some individuals find it difficult to deal with ambiguities and cognitive incompatibility with unfamiliar and new things. They show a general tendency toward binary thinking or general Polar thinking, seeing things and people as all good or evil. When these individuals are exposed to ambiguous positions, they find biased interpretations of their ideas and the dual thinking of dealing with ambiguous attitudes prevails in their ways of confronting their personal relationships and behaviors about people and things.

He tends to neglect others because of their beliefs that contradict his beliefs and show hostility as a defensive response to the threat of those who disagree with him is fanatic against other cultures because of his beliefs, the individual tends to adhere to the opinion and the tendency to resolve the definitive choice between white or black and divide things on the opposite sides and seek either absolute acceptance or absolute rejection.

The researcher believes that Polar thinking if left without the overlap of guidance, it contributes to the formation of an extremist personality in thinking and behavior and therefore, difficult to guide and treat.

Polarization thinking which is located at one of the two extremes is either white or black and Beck believes that psychological disorders result from the inconsistency between the internal cognitive system of the individual and the external stimuli that the individual is subjected to and analyzed by the system of internal knowledge that distinguishes it, the confusion of reality on the part of the individual in the event of disturbances may lead to a certain degree of disturbance of thinking which may create automatic ideas that seem to be acceptable from the point of view of the individual and therefore, reasonable for him. He may interpret all events as being applicable to him and then focus on himself which is called personal representation and is thought of as extremism which is known as Polar thinking (Muhammad, 2000). Many societies are affected by many factors that affect them. 
The most important factors are the genetic factor and the environmental factor. The genetic factor means the inherited inheritance of the human being through the genome of the chromosomes. Recent studies have confirmed that all human characteristics and qualities of thinking are through these genes. The second world plays a major role in shaping the individual's thinking through the family, society and school. The world by Guilford (1959) found that there is a kind of thinking that divides objects into black and white that the individual feels that there are two ways of dealing with no problem either wrong or right (Guilford, 1959).

Some individuals carry negative images or thoughts about themselves and members of their community and only see weaknesses, mistakes and unpleasant incidents and do not look to the near future except from dark, pessimistic corners. They will become psychologically disturbed if left behind and not guided that is their negative thinking or it is the extreme that generates these psychological disorders. In this light, counseling and therapy require a cognitive theory to work to modify those misconceptions and negative and extreme thoughts (Stoudmire, 1998). Polar thinking may also cause many psychological disorders including anxiety and depression (Jaf, 2000). The importance of the current research can be summarized by the following points.

Theoretical importance: Highlighting the theoretical side of the world Beck in Polar thinking which was one of the cognitive distortions through the provision of endoscopy which can contribute to the enrichment library of the school cognitive behavioral.

Practical importance: Through the adoption and application of the scale of thinking for the Polar which can be used by the extension units in colleges and universities in the diagnosis of students in the variables mentioned as well as subject to those variables. The importance of university students as an important social segment and future leaders.

Third: Research objectives aims of the research. The current research aims to identify. Polar thinking among university students. The statistical significance of Polar thinking among university students according to the variables of gender (male and female) b specialization (human sciences).

Fourth: Limits of the research limitations the current research is determined by the students of the universities of the Middle Euphrates (Babylon University, Karbala University, Kufa University, Qadisiyah University), males and females and the scientific and humanitarian disciplines for the academic year $(2017,2018)$.
- Fifth: terminology terms limitations

- Second: polarization thinking

- Known by Neuringer (1961), neuringer

- Naming events as white or black, good or bad, wonderful or outrageous" (Neuringer, 1961)

Beck (1991, 1995, 2000): The thinking that classifies events into black or whites and the individual may not give himself a wide space to decide he either sees himself skillful "successful" or sees himself as a complete failure (Corey, 2000).

Hamid and Kafafi (1990): "Cling to the ideas and beliefs of the individual and the unwillingness to discuss other ideas to convince him of wrong and deviation".

Theoretical definition: The researcher adopted the definition by Aaron Peck of Polar thinking.

Procedural definition: The degree to which the respondent obtains through his answer to the paragraphs of the Polar thinking scale.

Polarization thinking: The concept of thinking the concept of thinking in psychology in other sciences and in life in general occupies a central place because the task of thinking is to find suitable solutions to the theoretical and scientific problems that a human being faces in society and constantly renews which constantly leads to the search for new methods and methods that enable him to overcome the difficulties and obstacles that arise, its future prominence and which gives it an opportunity to progress and advance.

Thinking as a cognitive process is an essential element in the mental and cognitive structure that man possesses and is characterized by his social nature and his systemic work which makes him interact with the elements of the building which influences and influences the rest of the cognitive processes such as perception, perception, memory, affect and affect the emotional. Thinking about other cognitive processes as the most sophisticated and complex and able to access to the depth of things and phenomena and attitudes and knowledge which enables the processing of information and the production and re-production of new knowledge and information.

The word "thinking" as many researchers point out is not specific either in the language of daily life or in the language of psychology. It may refer to many different types of behavior and to different types of situations, so, it is difficult to define a thinking or to choose a specific definition of it. And identify the manifestations in which it is manifested. Thinking in its general sense is a mental or mental activity that differs from feeling and perception and goes beyond both to abstract thoughts. The narrow 
and specific meaning is all flow or flow of ideas, driven or provoked by a problem or issue that requires solution. It also leads to study, its validity and the knowledge of the laws it controls and the mechanisms under which it operates.

The views of scholars and educational researchers differ on the general definition of thinking if they present different definitions based on multiple theoretical foundations and trends. Each individual has his own style of thinking which is related to the style of his development his motivation his abilities his cultural background and other distinguishing features from others. Led to the absence of a unified vision among scientists on the definition of thinking and its characteristics, forms and methods.

Psychologists call the word thinking as a generic term for various mental activities such as inference, problem solving and conceptualization. Do people think of thinking in words? Or mental images? Or is their thinking another way? Psychologists can not directly observe the thoughts of any individual but they address this problem indirectly. In one of the earlier studies on this issue, the English psychologist Galton invited some individuals to think about their breakfast table and then asked his subjects about the clarity of their mental images, he found that some of them described very vivid images while others did not call for anything and mental images seemed to be an important component of many people's ideas (Davidoff, 1987).

Thinking is the process by which mental representation is formed. Thinking is a general term that encompasses all types of symbolic activity. It includes reasoning, imagining and the formation of total meanings and innovation and uses thinking as substitutions of real things and real situations that is it uses symbols that represent objects or conditions and the symbol is anything: meaning an image, the place of something else responds in the same way that we respond to the same thing.

De Bono, defines thinking as the process by which intelligence performs its activity on experience that is it includes the ability to use inherited intelligence and bring it to the ground as it indicates a discernible or careful discovery of experience in order to reach the goal.

It is a function of personality that is related to human activity and Barrell has defined it as a series of invisible mental activities performed by the brain when a man is received by one or more senses in search of a specific meaning, thinking is what the brain does. De Bono believes that thinking is "the deliberate investigation of experience in order to reach a goal and this goal may be understanding, deciding, planning, solving a problem, judging things or doing something." Baer defined it as "a mental process through which the learner can do something meaningful through his experience".
Thinking is a virtual concept that refers to an internal process that is attributed to a cognitive, cognitive, interactive, intentional, cognitive activity directed at solving a particular issue or decision or satisfying a desire to understand or find meaning or answer to a question and develop in the individual according to its surrounding environmental conditions.

Thinking is what moves in the mind from pre-action processes that is we begin to understand what we feel and then work to assess what we understand trying to solve the problems we face in daily life. In short, thinking is a complex concept consisting of three elements: complex cognitive processes, primarily solving problems and less complex such as understanding and application and then knowing the content of the subject or subject matter.

Chapter III: This chapter includes a description of the research procedures carried out by the researcher for the purpose of achieving the current research objectives. The procedures of this research include determining the scientific research methodology followed, identifying the research community, selecting a representative sample, the method of selection, its specifications and homogeneity and building and applying appropriate tools that are characterized by honesty, consistency and objectivity used in data processing.

Research approach: The study of any phenomenon "psychological, educational, social" requires the researcher to follow a scientific methodology to be followed by the researcher and that the nature of the subject and the purpose of which is imposed on the researcher type of approach to be followed. Therefore, it was appropriate in this research to choose a suitable approach to the characteristics and quality of the study followed and since, the current research aims to study Polar thinking and to gain a deeper understanding of the phenomenon studied as the descriptive approach does not stop when describing the phenomenon but beyond analysis and interpretation and comparison to reach more information. For this phenomenon, the descriptive approach is a scientific diagnosis of a phenomenon and its quantification and linguistic and mathematical symbols (Daoud et al., 1990).

Research community population of research: The current research community consists of students from the Middle Euphrates University (Babylon, Karbala, Qadisiya and Kufa) for the academic year (2017-2018). About 90,84 male and female students 41,780, males 48,804 and human and scientific subjects. The total of the University of Babylon (25712) students (11808) of them male and (13904) of females. The total number of students at Karbala University was 20,072, 9,136 were males and 10,936 were females while the total number of students at Al-Qadisiya University was 17560 students, 8232 were males and 9328 were females. 
The Soc. Sci., 14 (11): 361-369, 2019

Table 1: Test results for one sample of the Polar thinking scale

\begin{tabular}{|c|c|c|c|c|c|c|c|}
\hline \multirow[b]{2}{*}{ Level of significance $(0.05)$} & \multicolumn{7}{|c|}{ t-values } \\
\hline & Table & Calculated & Mean medium & SD & Arithmetic mean & Sample & Variable \\
\hline Function & 1.96 & 17.27 & 78 & 10.46 & 87.04 & 400 & $\begin{array}{l}\text { Polar thinking } \\
\end{array}$ \\
\hline
\end{tabular}

Table 2: Results of the analysis of binary variance $2 \times 2$ to examine the effect of study variables (gender and specialization) in Polar thinking level of significance $\mathrm{p}$ value $\mathrm{t}$-value $\mathrm{p}$-calculated mean squares free degree total squares of source of variation

\begin{tabular}{llccrr}
\hline Not a function/function & Sex & Specialization & Sex*Specialization & The error & Total \\
\hline 3.84 & 0.01 & 7.58 & 1.31 & 107.90 & 390.00 \\
& 0.81 & 817.96 & 141.61 & 42730.98 & 43691.36 \\
& 1.00 & 1 & 1 & & \\
\hline
\end{tabular}

Research sample the sample of research: The sample was randomly selected from the research community which is represented by the universities of the Middle Euphrates (University of Babylon, Karbala University, Al-Qadisiyah University, Kufa University). The sample number was 400 students with 200 students and 200 students from the research community Middle Euphrates Universities.

Fourth; instrument of research: The objective of the tool is to identify the property to be measured (Anastasi, 1976). In order to achieve the current research objectives.

Adoption of the Polar thinking scale: Since, the current research aims to know the Polar thinking of university students, so, it requires the presence of a tool in which the characteristics of psychometric to achieve the objectives of the research which is as follows.

Polar thinking scale: The researchers adopted the Polar thinking scale which was prepared and codified by researcher Shaker Hamed Rashid in his thesis for the Master in (2016) which consists of 29 paragraphs. Where the researchers found that this measure can be used for the purposes of the current research after the extraction of the properties of psychometric. The researchers adopted the criterion (2016) for Polar thinking as the only measure available for the measurement of Polar thinking which was prepared on the Iraqi environment which was applied and the extraction of the characteristics of the psychometric students of the current research community itself, they are university students and the scale consists of 29. The first field: the absolute positive outlook for the self and consists of 14 paragraph and the second area: the absolute negative view of the self and consists of 15 paragraph.

Specify the scale areas: Polar fields of polarization were confined to the concept presented by Beck in. The first area the absolute positive outlook of the self the individual's view of himself is a positive exaggeration, absolute in which there is nothing negative or weak.
The second area: The negative view of the absolute self the negative view of the individual to himself and it is weak and inferior "of others there is nothing positive.

Setting meter instructions: The instructions of the meter included how to answer the paragraphs and inform the respondents of the need for accuracy in the answer and the researcher deliberately to hide the goal of the scale, so that, the respondent is not affected by the answer and therefore included the instructions of the scale that the answer to the paragraphs of the scale honestly and objectively and leave no paragraph without answer and that the answers will be confidential and will not be seen by anyone but the researcher and is used for scientific research only.

Validity of paragraphs: For the purpose of verifying the validity of the paragraphs of the scale in its initial form, it was presented to a group of arbitrators specialized in the educational and psychological sciences to show their validity. After the arbitrators expressed their opinions on the validity of each paragraph of the scale, it became clear that all the paragraphs of the scale obtained the consent of the arbitrators some paragraphs were amended in the light of their observations.

Table 1 and 2 shows that the value of the calculated square of KAI was a function of 28 paragraphs. The calculated value of (12.8) is greater than the value of the square Ki square (3.84) at a significance level (0.05) one freedom thus, accepted all paragraphs of the scale.

Exploration experiment: The researcher applied the scale to the sample of the same exploratory experiment used in the scale of beliefs of amplified responsibility. The researcher explained to the students that the standard is intended for scientific research purposes. There is no correct answer and the wrong one. The responses of the sample of the survey sample on the scales of the scale R. Researcher, so that, they can answer what they put forward queries and questions regarding the paragraphs of the scale and through the application. Expeditionary of the measure shows that its instructions and its paragraphs 
were clear and understandable to Mvhusin has ranged from the time it takes to answer between 15-20 min at an average of 17.5 flour.

Description and correction of the meter: The number of paragraphs of the scale 28 divided by 2 areas: the absolute positive outlook for the self and the number of paragraphs 14 paragraph, the absolute negative view of self and the number of paragraphs 14 .

The answer on the scale consists of five alternatives: (always apply to me, apply to me often, apply to me sometimes, rarely apply, never apply) the first alternative is given five degrees, the second alternative is four degrees, the third alternative is three degrees and the lowest grade with a mean average of 84 degrees.

Statistical analysis of paragraphs: One of the requirements for the preparation and development of paragraphs of psychological measures is the statistical analysis it reveals some of the characteristics of the cycometric paragraphs including the internal homogeneity of the scales of the scale which is an indicator of the validity of the scale (Anastasi, 1976).

Therefore, the polarization tool was applied to the same sample of analysis that was applied to the scale of the beliefs of the maximized responsibility of 400 students. After that the power of each parameter was calculated as well as the internal consistency of each. As described below. The unique power of the Polar thinking scale paragraphs. The researcher extracted the discriminatory force of the paragraphs in the following manner. The power of the standard clauses in the two groups.

For the purpose of finding the differential force of the scale sections in the way of the two groups, the researchers followed the $27 \%$ upper $27 \%$ minimum and the procedure.

Two squares which have a sequence $(5,13)$ in the scale, fell because the calculated t-value was smaller than the tabular t-value of 1.96 at the degree of freedom (214) and the level of significance (0.05). Number of paragraphs of the scale 26 paragraph only.

Relationship of the paragraph to the total: There was no drop of any paragraph because the calculated correlation coefficient $(\mathrm{T})$ for all the paragraphs was greater than the value of $(t)$ of the scale (0.098) at the level of significance (0.05) and the degree of freedom (398).

Relationship of the paragraph to the domain to which it belongs: The relation of the degree of the paragraph to the field to which it belongs to the poles of the Polar reflection scale.

$\mathrm{T}$ of the two domains was not subtracted because the calculated correlation coefficient $(t)$ for all the domains of the two fields was greater than the value of $t$ of the scale $(0.098)$ at the level of significance $(0.05)$ and the degree of freedom (398).

\section{Relationship of domains to the scale as a whole Indicators of sincerity and stability}

Validity indexes: Van Dalen points out that the means of measurement are true if they measure what is called measurement. He also pointed out that honesty is one of the most important elements of the test (Hassanein, 2001). Therefore, it was ascertained the availability of the apparent honesty and honesty of the building of the "Polar thinking scale" as follows:

Face validity: This type of honesty was achieved for the Polar thinking scale when the researcher presented the paragraphs of this scale in its fields and its instructions and alternatives to a group of arbitrators in the educational and psychological sciences who agreed on the validity of the standard paragraphs and its instructions and alternatives. Which was presented to the same experts at the same time. Promise each valid paragraph when the value of the calculated KAI box is statistically significant at the 0.05 level and one degree of freedom (as described in the paragraph above).

Construct-validity: This type of truth is achieved by means of the indicators of the statistical analysis of the paragraphs in the way of the two groups. The relationship of the degree of each paragraph to the total degree of the measure and its ability to distinguish and homogeneity of the paragraphs, the relationship of the degree of each paragraph in the field to which it belongs and also the correlation between the degree of each field and degree college of scale.

Reliability indexes: Stability means consistency, meaning that the degrees of the individual do not change substantially by repeating the test on him (Hassanein, 2001). The stability of the scale was extracted in two ways.

\section{MATERIALS AND METHODS}

Test-retest method: The researcher used the method of re-testing to extract the coefficient of constancy. The researcher applied the Polar thinking scale to the same sample on which the amplitude paths of beliefs were applied. The coefficient of stability was 0.76 . This value is acceptable for scientific research purposes and can be relied on.

Correlation coefficient of alpha-Cronbach for internal consistency

(Alfa coefficient for internal consistancy): To calculate persistence in this method, the researcher 
relied on the sample of the application of the stability account in the method of (test-retest). After applying the alfa Cronbach formula for internal consistency, the alpha-Cronbach method: 400 students and then applied the alpha-Cronbach equation for the purpose of extracting the stability of the scale where the coefficient of stability of the Polar scale of thinking in this way 0.69 . This value is acceptable for scientific research purposes and can be relied upon.

For the purpose of achieving the objectives of the current research and after confirming the validity of the search tool and stability has become a measure of Polar thinking in the final version of the component 28 paragraph consists of two areas: the field of absolute positive outlook of the self and consists of 14 paragraph, the absolute negativity of the self consists of 14 paragraphs and before each paragraph there were five alternatives to the answer (which apply to me always, apply to me often, apply to me sometimes, apply rarely, "never apply").

The researcher began applying the research tools on the basic research sample from the universities of the Middle Euphrates (400) students from the universities of the Middle Euphrates (Babylon University, Karbala University, Kufa University, Qadisiyah University) of both sexes and scientific and humanities. After the application of the OCD measure to the research community, the researcher obtained this sample of 400 students and students. It took the period to apply the scale from 2018/2018. The researcher was keen to distribute the scale forms under her supervision, so that, students can answer in order to help the student to be in a state of psychological and mental good and after the distribution of measurements on the students asked the researcher to write the data on the answer sheet after i explained how to answer the paragraphs of the scale and give them an illustrative example and that their answers will be confidential and will not be seen by anyone but the researcher and after the completion of the students answers collected forms according to gender and specialization, so that, the researcher ease of correction and statistical processing of data to extract the results.

\section{RESULTS AND DISCUSSION}

Statistical means: The researchers used the statistical file (SPSS) to process the data the fourth chapter view and interpret results.

First, view and interpret the results: This chapter includes a presentation of the results of the current research in accordance with the objectives set out in the first chapter and interpretation in light of the theoretical framework and previous studies and through the application of research tools on the basic character and statistical analysis of the data obtained, the sequence of objectives. The chapter also contains a set of conclusions, recommendations and proposals related to the current research results as follows.

The first objective: To identify the Polar thinking among the university students. In order to achieve this goal, the Polar thinking scale was applied to the sample. After the data was unloaded and processed statistically, the arithmetic mean and the standard deviation of the student's scores were found. The mean of the scale was 87.04 and the standard deviation was 10.46 . To find out the difference between the real mean and the mean average for the sample use the t-test for one sample as shown in Table 1.

Table 1 shows that the calculated $t$ value is 17.27 which is greater than the tabular $t$ value of 1.96 at the level of significance (0.05) and the degree of freedom (399), indicating that there are statistically significant differences this may be explained by the fact that some individuals tend to be aware of things either white or black, malignant or good, honest or false, right or wrong without realizing that the thing the one that may look bad from their point of view may have positive things that is Polar-minded individuals tend to confront the mu different and diverse which they are exposed to it in one way of thinking does not accept the opposition to their ideas stand and be an individual with a Polar that has a lock in the beliefs espoused by thinking which leads to that converts ideas open has a closed system of ideas does not accept the discussion and dialogue with those who oppose it in his thoughts their approach to thinking is linked to any ideology regardless of its content. Its strong attachment to beliefs distorts its ability to think logically, impeding its ability to solve problems and productive thinking and has limited ability to organize and differentiate new ideas and between the ideas held in the face of problems (Salama, 1984; Monthly, 2005).

And be their way of closed thinking is characterized by inertia, intolerance and narrow-mindedness, thinking hyperbolic and to have the look and bullying in life and do not bear people who disagree with their ideas or beliefs of their own and tend to people who have their ideas and beliefs are similar with their thoughts and beliefs and be and the polarized individual is characterized by strictness with those who have ideas against him without trying to identify those ideas and that the conception (Aaron Peake) of Polar thinking is based on his perception on the nature of man that is for every human being $\mathrm{N}$ point of view building of knowledge (cognitive structure) and this knowledge building on the ideas that believes are an individual each person shall have its own life beliefs and also beliefs about power and social, cultural, political and economic relations and relations with other individuals, and be the organization of these beliefs in a particular 
format or a particular system (system) total, this macro echelon is building knowledge of the individual's privacy and may accrue based on the construction of cognitive thinking and behavior of many trends of the individual which may be described as the ideas and behaviors and trends of closed or rigid methods, it may also be described as directions open minded and able to coexist and communicate with the beliefs, attitudes and ideas of other individuals (Dillehay, 1969).

The second objective: To identify the differences of statistical significance of the Polar thinking among the university students according to the variables of gender (male and female) $b$ specialization (human sciences).

To achieve this goal, the Polar thinking scale was applied to the sample of the research sample. The data obtained from the application were then collected. The average of the Polar thinking of the male sample was 86.99 and the average of the female sample was 87.08. About 85.61 and the average score of human specialization (88.47). In order to identify statistical significance differences in Polar thinking based on sex, specialization and impact from interaction between the two variables, this was tested using the two way analysis of ANOVA as shown in Table 2.

In Polar thinking: Level of significance $p$ value t-value p-calculated mean squares free degree total squares of source of variation. Table 1 shows the following results the impact of sex (male-female).

Table 2 shows that the calculated alpha value is 0.01 which is smaller than the maximum numerical value of 3.84 at the level of significance (0.05). This indicates that there are no statistically significant differences in Polar thinking depending on the type of student.

The effect of specialization (scientific-human): the table shows that the calculated alpha value is 7.58 which is greater than the numerical value of 3.84 at the level of significance (0.05). This indicates that there are statistically significant differences according to specialization and for human specialization. About 88,47 which is higher than the average degree of scientific specialization $(85,61)$. This indicates that the students of the human branch have a Polar mind. This is because the curriculum in human specialties tends to one direction of thinking rather than multiple directions the student in the human disciplines adheres to the ideas and philosophies of these ideas. The student responds positively to the courses that have to do with the humanities and their curricula, especially, students with human specialization are influenced by the nature of their specialization their curricula, teaching methods and the environment surrounding them. They do not try to develop themselves and their way of thinking. Its exposure to cognitive malformations and their thinking is limited, either white or black, so their interaction with things either positive or negative, contrary to the scientific disciplines and the reason that their curricula that urge them to think logically and in different ways and variety of thinking. Through their continuous knowledge of modern methods, scientific technology and the methods they use in their scientific applications of their subjects and their use of scientific reasoning and reasoning and their use of experimentation, this makes them less susceptible to cognitive distortions and Polar thinking that affect their cognitive abilities and mental processes while human disciplines are more susceptible to cognitive malformations their thinking either negative or positive either black or white which affects their thinking, abilities and mental processes and this in turn is reflected on their daily life in particular and their university life in general and be their negative view of the things and things around them either positive Tor negative as well as their view of the world and society and the future around them be either positive or negative.

Interaction between sex and specialization: Table 1 shows that the calculated alpha value is 1.31 which is smaller than the numerical value of 3.84 at the level of significance $(0.05)$. This indicates that there are no statistically significant differences between sex and specialization. Indicates that the levels of the first variable have no effect on the levels of the second variable, thus, it can be said that there is no element of interaction between the sex variables and specialization in Polar thinking.

A function in specialization and in favor of the human because their arithmetic mean is greater than the arithmetic average of the scientific specialization as shown in below.

\section{CONCLUSION}

The results showed what; the presence of Polar thinking among university students. There are differences of statistical significance according to gender variable. There are differences of statistical significance for the benefit of human specialization. The research came out with a set of recommendations and proposals.

\section{REFERENCES}

Anastasi, A., 1976. Psychological Testing. 4th Edn., Macmillan, New York, USA., ISBN-3:978-0023029806, Pages: 750.

Azirjawi, A.A.H.A., 2007. Intellectual hardness and its relationship to sex, specialization and spiritual direction material and methods of parental treatment of University students. Ph.D Thesis, University of Baghdad-Ibn Rushd College, Baghdad, Iraq.

Beck, A., 2000. Cognitive Therapy and the Emotional Disorders. Dar al-Nahda Arab Printing and Publishing, Beirut, Lebanon,. 
Beck, A.T., 1991. The Evolution of Psychotherapy. Bruner-Mazei, New York, USA.,.

Beck, J.S., 1995. Cognitive Therapy: Basics and Beyond. Guilford Press, New York, USA., ISBN:9780898628470, Pages: 338.

Corey, G., 2000. Theory and Practice of Counseling and Psychotherapy. Thomson Brooks Cole, Australia,.

Daoud, A. Hanna, A. Rahman and A. Hussein, 1990. Educational Research Methods. Baghdad University Press, Baghdad, Iraq,.

Davidoff, L.L., 1987. Introduction to Psychology. 3rd Edn., McGrawhill Publishing House, Saudi Arabia, ISBN:9780070155701, Pages: 598.

Dillehay, R.C., 1969. Sincerity and dogmatism: A reassessment and new data. Psychol. Rev., 76: $422-424$.

Fiske, S.T. and S.E. Taylor, 1991. Social Cognition. 2nd Edn., McGoo-Hill, New York, USA.,.

Guilford, T.P., 1959. Personality. Megraw-Hill, New York, USA.,.

Hamid, J.A.J and A. Kafafi, 1990. [Dictionary of Psychology and Psychiatry Part III]. Dar Al Nahda Cafeteria, Sharjah, United Arab Emirates, ISBN:978977519, (In Arabic).

Hassanein, M.S., 2001. Measurement and Evaluation in Physical Education and Sports. Dar Al Fikr Al Arabi, Cairo, Egypt,.

Ibrahim, A.S., 1998. Modern Cognitive Behavioral Therapy: Methods and Fields of Application. The Arab House for Publishing and Distribution, Nasr City, Cairo, Egypt,.

Ibrahim, A.S., 2000. Cognitive behavioral psychology. Master Thesis, King Faisal University, Hofuf, Saudi Arabia.
Ibrahim, I., 1990. The study of irrational thinking in relation to anxiety and personal orientation in a sample of university youth. Master Thesis, Zagazig University, Zagazig, Egypt.

Ibrahim, I.E.S., 1993. The relationship between the level of moral judgment at the level of dogmatism in three samples of secondary students. Master Thesis, Tanta University, Tanta, Egypt.

Jaf, K.H.K., 2000. The question of presence in the philosophy of martin Heidegger. Master Thesis, University of Baghdad, Baghdad, Iraq.

Monthly, H.R., 2005. The level of intellectual closure (Dogmatip) for teachers and teachers of the stages of public education in Medina. Message Educ. Psychol., 27: 279-334.

Mostafa, M.E., 2008. Cognitive Behavioral Therapy Brief. ITRAC for Printing, Publishing and Distribution, Cairo, Egypt,.

Muhammad, A.A., 2000. Studies in Social Psychology. Dar Qab'a for Printing, Publishing and Distribution, Cairo, Egypt,.

Neuringer, C., 1961. Dichotomous evaluations in suicidal individuals. J. Consulting Psychol., 25: 445-449.

Salama, M.A., 1984. The relationship of dogmatism to the level of education and educational attainment among Qatari adolescents. Bull. Faculty Educ., 1: 1-25.

Stoudmire, A.M., 1998. Clinical Psychiatry. Lippincott Williams \& Wilkins, Philadelphia, Pennsylvania, USA.,.

Zawawi, R.M.S., 2011. Pragmatical thinking and its relation to ethical thinking in a sample of rashidiya in the city of Mecca in light of some demographic and social variables. Master Thesis, Umm Al Qura University, Saudi Arabia. 